\title{
Estamos formando professores que conhecem a variação linguística? Uma análise acerca da importância dos dados e das teorias para o ensino de língua
}

\author{
Are we preparing teachers who know linguistic variation? An analysis on the \\ importance of linguistic data and theory to language teaching
}

Taís Bopp da Silva*

\begin{abstract}
RESUMO: Os trabalhos sobre variação do português brasileiro (PB) avançaram no sentido de documentar e explicar a língua. Percebe-se, contudo, um abismo separando ensino e pesquisa, pois o conhecimento científico não tem extrapolado, em todas as suas potencialidades, as fronteiras dos muros acadêmicos. Observa-se, paradoxalmente, que o mercado editorial sobre ensino de língua materna cresce com vigor, porém, privilegia aspectos pedagógicos e metodológicos, como que normatizando a conduta do professor, pouco explorando a apresentação dos fenômenos variáveis. Nesse sentido, se já não formamos mais professores voltados para a defesa do purismo linguístico, como há alguns anos atrás, hoje formamos profissionais muito bem treinados para o discurso acerca da variação, mas com pouco conhecimento dos fenômenos variáveis. Isso se evidencia no modo como alguns desses profissionais classificam certas variantes estigmatizadas: "diferente", "não quer dizer que é errada", "apenas inadequada" - o que deixa entrever o predomínio de um tom valorativo (com o cuidado de ser politicamente correto) no modo como descrevem tais variantes. O papel da sociolinguística, no entanto, consiste não apenas em promover a tolerância à variação, mas levar à compreensão de seus mecanismos.

ABSTRACT: Works in Brazilian Portuguese variation field has shown advances in description and explanation levels. However a gulf between academic research and teaching has been noticed since scientific results remain into the scholar circles. Paradoxically, publications on mother language teaching have been spread, however focusing on pedagogic methods instead of variable phenomena presentation. In this sense, although the model of traditional teacher is not the standard anymore, universities fail to graduate professionals who know variable phenomena; differently, these are mostly prepared just to support the talk in favor of language variation acknowledgement. This become evident by the way some teachers qualify certain stigmatized variants as "different", "not wrong", "only inappropriate" - what suggests an evaluative attitude towards these variants. The role of sociolinguistics, nonetheless, consists not only of promotion of tolerance of variants but explanation of their mechanisms. In this article, we aim to gather some contributions of sociolinguistics to language teaching in order to discus whether it has accomplished the task of showing the linguistic diversity or it just represents a way to regulate teaching practices and teacher behavior.
\end{abstract} Neste artigo, buscamos reunir algumas das contribuições da sociolinguística para o ensino de língua e discutir se essa disciplina tem cumprido a tarefa de mostrar ao professor a pluralidade linguística (o que é necessário para que ele perceba como legítimas as

\footnotetext{
* Centro de Letras e Comunicação da UFPel.
} 
variedades com as quais vai se deparar em sala de aula) ou tem se limitado a normatizar comportamentos desejáveis ao professor, constituindo, assim, mais uma fonte reguladora da prática docente.

PALAVRAS-CHAVE: Variação e Ensino. Contribuições da Sociolinguística. Sociolinguística e Comportamento.
KEYWORDS: Language variation and teaching. Developments of sociolinguistics. Sociolinguistics and teacher's behavior.

\section{Introdução}

Os estudos sobre linguagem no contexto social seguem diversas tendências e vêm se consolidando desde o século XIX. Através da perspectiva dialetológica (AMARAL, 1920; NASCENTES, 1923), pelo viés geolinguístico (CARDOSO, 2010), ou por meio da sociolinguística quantitativa (a partir do modelo de LABOV, 1966), a descrição do português brasileiro mostra-se hoje um movimentado campo de pesquisas, com muitos fenômenos já documentados. Do mesmo modo, a sociolinguística interacional e a etnografia da fala vêm levantando e discutindo problemas no que tange ao uso da língua.

Quando se fala no ensino de língua materna, é de conhecimento dos linguistas que, em grande parte dos estabelecimentos escolares, a imagem do português que se tentou perpetuar durante muito tempo foi aquela de língua unificada e subordinada aos padrões do português europeu. Essa realidade, contudo, vem aos poucos se modificando. A propagação dos achados da ciência linguística, por um lado, e a relativa democratização do acesso ao ensino, por outro, redimensionaram a visão sobre língua e, consequentemente, sobre o modo como é ensinada na escola. Essa nova visão passa por uma revisão da noção de erro linguístico e tem como reflexo a desmitificação da língua literária ${ }^{1}$. Essas mudanças, em conjunto, desembocam numa crise no ensino da língua materna, como veremos.

Com o presente artigo, objetivamos apresentar os principais campos de pesquisa da disciplina denominada sociolinguística, trazendo aspectos, de cada uma, que julgamos contribuir para qualificar o ensino de língua portuguesa no Brasil.

Iniciaremos apresentando um breve panorama da educação no país; em seguida, faremos uma exposição dos principais campos da sociolinguística, relacionando-os com o ensino de português. Fechamos o trabalho com uma reflexão acerca do aproveitamento da pesquisa

\footnotetext{
${ }^{1}$ Por "língua literária" queremos designar o registro, escrito ou oral, utilizado na veiculação de informação, na transmissão de conhecimento e na produção e divulgação cultural.
} 
variacionista na formação do professor, discutindo o papel das descrições linguísticas, a dinâmica método-conteúdo e o atual estatuto da gramática. Discutiremos, sobretudo, se a sociolinguística tem cumprido seu papel de mostrar ao professor de língua materna a real dimensão da variação do português, ou se o que chega a ele é apenas um discurso esvaziado acerca de uma variação que sequer compreende e do qual, porém, deve se apropriar. Não pretendemos, com este artigo, oferecer fórmulas prontas para o professor ou prescrever soluções. Nosso objetivo é apresentar o conhecimento que cada área dos estudos sociolinguísticos tem produzido, esperando auxiliar os profissionais da área na escolha de caminhos para trabalhar de forma autônoma e crítica, de modo a buscar alternativas para seus impasses.

\section{Breve panorama da educação no Brasil: o novo público da escola}

A crise no ensino de língua portuguesa não é apenas uma crise de método; é, sobretudo, uma crise social. É uma crise social porque reflete duas grandes transformações, segundo nosso entendimento. A primeira transformação diz respeito à mudança do público que passou a frequentar a sala de aula, que se mostrou mais heterogênea a partir dos movimentos migratórios. A segunda transformação social está relacionada com o prestígio da linguística como ciência, quebrando certas crenças e paradigmas. Iniciemos explorando o primeiro ponto.

Conforme Bortoni-Ricardo (2004), na década de 1960, a população urbana passou a constituir $45 \%$ da população total do país. Na escola, a migração de populações rurais para as cidades apresentou uma diversificação social e cultural ao professor. Passaram a conviver lado a lado crianças oriundas de culturas e classes sociais diferentes, detentoras de diferentes falares, que espelhavam principalmente sua condição econômica e sua origem geográfica. A distância cultural que separava as crianças de origem rural das demais crianças e, principalmente, dos seus professores, formados para doutrinar seus alunos no uso de um português qualificado como correto, acabava por desestimular essas crianças, que, então, abandonavam a escola ou apresentavam rendimento abaixo do esperado. Uma política linguística que levasse em conta tal diversidade sócio-cultural fazia-se necessária naquele momento. Contudo, um planejamento com vistas a acolher essa população culturalmente marcada é algo que não se verifica na realidade escolar ainda nos dias de hoje.

Se, conforme apontamos acima, a pesquisa em linguística tem mostrado grandes avanços e, ao mesmo tempo, faltam políticas linguísticas nas escolas, é pertinente nos 
perguntarmos sobre qual o papel de tais pesquisas no desenvolvimento de planejamentos educacionais. O papel social da ciência é matéria bastante debatida, mas, dada a nossa limitação de espaço, não nos debruçaremos aqui sobre esse assunto. É fato inegável, no entanto, que existe uma lacuna entre ensino e pesquisa, uma vez que o conhecimento produzido pelos pesquisadores brasileiros tem ficado restrito ao ambiente acadêmico, sendo poucas as propostas que visam fazer uma ponte entre o científico e educacional.

\section{A ciência linguística e as principais vertentes da sociolinguística}

Na medida em que a linguística concebe a língua como organismo que se autorregula isto é, que independe de uma regulação externa, normativa -, acaba relativizando os chamados "erros" linguísticos.

Tendo em vista que o erro é uma noção de grandes implicações nas questões de ensino, a linguística passa a estabelecer alguns pontos de intersecção com a pedagogia. Mais do que apontar para a heterogeneidade linguística, mostrando que a língua pode variar no eixo diatópico (que diz respeito à localização geográfica em que está inserido o falante) e no eixo diastrático (de acordo com aspectos sociais), as pesquisas em variação e descrição do português brasileiro têm avançado bastante na construção de uma gramática daquilo que de fato ocorre no português do Brasil, o que respaldaria um programa de ensino baseado em nossa realidade. Fica evidente, enfim, que os achados da linguística, de algum modo, confluem com os objetivos do ensino de língua.

A sociolinguística, por estar mais diretamente ligada a aspectos sociais, supomos ser a disciplina linguística que mais diretamente poderia contribuir para o planejamento das aulas de língua materna. Vejamos um pouco do que essa disciplina tem a oferecer aos professores no que diz respeito ao planejamento de suas práticas.

Primeiramente, devemos esclarecer que estamos fazendo uso do termo sociolinguística em sentido bastante amplo. Por "sociolinguística" estamos designando o estudo da linguagem no contexto social. Essa grande disciplina se subdivide em linhas que variam em seus objetivos específicos e métodos. Neste espaço, vamos apresentar as contribuições que a dialetologia, a sociolinguística quantitativa e a sociolinguística interacional trazem para o ensino de português. 


\subsection{A dialetologia}

A tarefa da dialetologia é mapear no espaço geográfico as variações de uma língua. A relação da língua com o espaço geográfico traduz-se na compreensão dos espaços geofísicos como espaços socioculturais. Nesse sentido, a dialetologia pressupõe que diferentes regiões geográficas apresentam diferentes modos de falar em decorrência de contextos culturais que lhes são particulares. Assim, fatores como o tipo de colonização predominante em uma localidade, os papéis representados por homens e mulheres e a mobilidade social de seus habitantes, entre outros, são responsáveis por desenhar a realidade linguística de uma região.

Tendo o pesquisador mapeado os traços linguísticos que caracterizam uma variedade regional, é possível definir o perfil do estudante falante de tal variedade e, assim, traçar estratégias de ensino que facilitem o processo de aprendizagem. Nesse ponto, é importante pensarmos acerca daquilo que acreditamos serem os meios facilitadores do aprendizado. Facilitar o processo não significa suprimir conteúdos ou minorar sua complexidade pelo fato de estarmos lidando com falantes não usuários da norma culta. Entendemos que o conteúdo alvo de língua portuguesa deva ser o mesmo independentemente do perfil social do aluno. $\mathrm{O}$ ponto de partida desse ensino, no entanto, é que deve ser diferente, pois é necessário que, para compreender a importância de aprender uma outra variedade da língua (a norma), o aluno entenda a legitimidade da língua que traz de casa com todas as suas particularidades.

Falantes de variedades de contato do português com línguas de imigrantes muitas vezes são levados a crer, em seu processo de aprendizagem, que falam um português deturpado. Muitos desses falantes, ao entrarem em contato com outras culturas, no momento em que deixam seus lares para trabalhar ou estudar em outras cidades, experimentam um sentimento de inferioridade em relação à variedade que falam. Essa situação de desconforto com a sua identidade cultural poderia ser minimizada caso esse falante fosse levado a compreender que seu modo de falar é tão legítimo quanto qualquer um e que seus traços particulares são determinados por fatores geográficos e culturais.

A dialetologia é um campo de pesquisas relativamente antigo. Segundo Cardoso (2010), o primeiro brasileiro a dar sua contribuição para um atlas linguístico foi Visconde de Pedra Branca, em 1826. Mesmo após tantos anos, a disciplina não foi suplantada por outras, pois vários atlas linguísticos regionais estão em elaboração no Brasil, ou foram recentemente concluídos. É digno de menção o Projeto AliB (Atlas Linguístico do Brasil), um 
empreendimento de caráter nacional, em andamento, que busca mapear as variedades que compõe o português no país.

\subsection{A sociolinguística quantitativa}

A sociolinguística quantitativa não só mapeia, mas busca sistematizar a variação levando em conta outras dimensões (relativas a faixa etária, nível social, gênero, entre outras). Trabalhando com a idéia de que toda variedade linguística é sistemática, ou seja, é governada por um conjunto de regras, o sociolinguista busca definir os fatores linguísticos e sociais que motivam as regras variáveis. Além disso, o método quantitativo permite diagnosticar o grau de estabilidade de um fenômeno variável. Através de cálculos estatísticos, o pesquisador tem condições de apontar se duas variantes (por exemplo, "cantar" e "cantá", no caso em que está em jogo a manutenção do "-r" dos infinitivos verbais) estão competindo igualmente ou se uma delas é predominante a ponto de implementar uma mudança linguística.

Essa disciplina, que correlaciona a língua ao uso, ao contexto social, e, além disso, introduz a noção de regularidade para o campo da fala, traz algumas contribuições importantes para o ensino. A primeira delas é mostrar que a língua é um todo orgânico que é regulado pelo uso. $\mathrm{O}$ contexto social, as necessidades dos falantes e as pressões comunicativas são os responsáveis por dar forma à língua. Com isso, a língua jamais sofre restrições de forças prescritivas, de fora para dentro. Língua e uso se alimentam mutuamente, restando pouco trabalho à prescrição na construção da forma linguística.

Outro ponto fundamental é que, sendo a variação controlada por regras - no sentido de regularidade, e não no sentido da normatização -, fato é que os chamados erros ou desvios não são aleatórios. Os falantes não apresentam "erros" idiossincráticos, individualizados. Basta observarmos que, quando se caricaturiza um indivíduo de cultura minoritária, seu português é caracterizado pela presença de traços estigmatizados que, porém, são uniformes no sentido de figurarem na fala de um coletivo de indivíduos e não em um indivíduo isoladamente. Lembremos, por exemplo, que sempre o som representado por "l" é trocado pelo som de "r" ("praca" no lugar de "placa", mas nunca "plimo" no lugar de "primo", exceto em certas etapas de aquisição da linguagem), que o som representado por "lh" é trocado pelo som de "i" ("paia" em vez de "palha”, mas não “desmalhar” por “desmaiar”, a não ser em casos de hipercorreção), que a marcação de plural privilegia o determinante e nunca o nome ("os carro" e não "o carros"). 
A partir, então, do momento em que se admitiu a regularidade nos fenômenos variáveis e que se estabeleceu um método bem definido para sistematizar o aparente caos, muitas pesquisas de descrição do português do Brasil foram levadas a cabo. Consequentemente, podese dizer que um panorama da norma culta que de fato é usada no Brasil pôde ser vislumbrado. Esses trabalhos, que correlacionam fatos linguísticos a fatores sociais, além de serem amplamente divulgados em periódicos científicos, estão disponibilizados na Gramática do Português Falado, uma série que descreve o português da classe urbana culta a partir dos dados do Projeto NURC (Norma Urbana Culta). A partir do exame dos dados que compõem a norma culta real do português, o professor pode elaborar um planejamento mais realista do ensino de gramática, priorizando o uso da norma real e não a sua idealização.

\subsection{A sociolinguística interacional}

Há ainda um campo da sociolinguística que investiga como se dá a dinâmica da interação entre os falantes. O pressuposto para os linguistas dessa área é que o sucesso da comunicação não é apenas resultado das semelhanças ou diferenças gramaticais nas variedades de dois falantes; é algo que pode ser medido pelo compartilhamento de valores e crenças entre esses falantes.

Sabemos que muitos dos valores que cultivamos são decorrentes dos modelos sociais em que estamos inseridos. Conflitos interpessoais seriam, portanto, muitas vezes, resultado de uma diferença cultural no modo de entender o mundo. Modos de interação também são modos de entender o mundo. Fica evidenciado, por conseguinte, que muitos conflitos em sala de aula nada mais são que conflitos decorrentes das falhas na interação comunicativa e de colisões de crenças cristalizadas. Tendo esse entendimento, o professor estaria mais amparado para resolver conflitos comunicativos, dentre eles aqueles decorrentes de discriminação e intolerância linguística.

A análise de redes (BORTONI-RICARDO, 1985), por sua vez, pode ajudar o professor a compreender o público de sua sala de aula, melhorando a dinâmica da interação a partir do conhecimento do tipo de rede social da comunidade em que a escola está inserida. Algumas redes sociais se caracterizam pela sobreposição de vínculos entre seus membros (por exemplo, o médico de minha família é também meu vizinho), o que leva a uma maior informalidade na interação verbal. Em outras redes sociais, os indivíduos se relacionam com um número maior de pessoas, mas não predomina a sobreposição de vínculos (nesse caso, meu médico é apenas 
um prestador de serviço, o que restringe nosso contato aos momentos de consulta), o que gera uma pressão por mais formalidade nas interações.

O conhecimento do tipo de rede social em que estão inseridos seus alunos é fundamental para um professor. É necessário entender que muitas vezes um aluno que traz para a sala de aula uma linguagem mais informal não está sinalizando indisciplina, rebeldia ou resistência, mas o faz porque a sua comunidade como um todo tem na informalidade um consenso.

Como o papel da escola é mostrar ao aluno que a língua deve se adequar a determinadas situações de uso, o professor também deve estar atento à noção de competência comunicativa (Hymes, 1972). Esse conceito vem a se somar ao de competência linguística. Se a competência linguística diz respeito às regras subjacentes que governam a boa formação de estruturas da língua, a competência comunicativa se atém à obtenção da fala adequada a diferentes tipos de interação verbal, em um contínuo que vai do mais formal ao mais informal. $\mathrm{O}$ aluno deve ser levado a compreender que, para transitar de um estilo mais informal para um estilo mais formal, é necessária a aquisição de um repertório linguístico em muitos pontos diferente daquele que traz de casa, ou seja, um repertório aprendido via instrução formal. Como consequência, o aprendizado deixa de ser visto como substituição de uma variedade linguística por outra, pois, na verdade, o aprendiz está apenas agregando novos modos de usar a língua.

\section{Refletindo sobre a relação entre teoria e prática}

A partir da exposição feita acima, evidencia-se que o ensino de língua materna pode ter forte amparo em pesquisas tanto sobre a real língua que falamos quanto sobre interação linguística. A pergunta a que chegamos é, então, a seguinte: por que há crise no ensino de português?

Vivenciamos, sim, uma crise no ensino de português, apesar de tanta pesquisa e do crescimento da produção bibliográfica destinada ao aperfeiçoamento dos professores. Se há alguns anos imperava um ensino rígido de gramática, com fins normativos, mais do que comunicativos, pode-se dizer que, hoje, vivenciamos um pouco do oposto. Muitos professores deixam entrever, por meio de seus discursos supostamente inclusivos, a idéia de que "não é preciso ensinar português na escola porque o aluno já sabe português". Paralelamente, esses mesmos professores - ou o aluno de letras quando em estágio curricular - sentem-se desamparados e inseguros para preparar um projeto de ensino fundamentado na ideia de que "não é necessário ensinar português". Vive-se, pois, uma crise no ensino de língua materna. 
Como já foi dito, essa crise tem raiz em fatores diversos. Um dos mais notáveis é o equívoco no manejo de noções como "ensinar", "português" e "gramática". Sabemos que "ensinar", no que diz respeito ao ensino formal da língua materna, carrega o sentido de aprimorar, de ampliação do repertório linguístico. "Português", por sua vez, são vários: pode ser aquele que falamos em casa, aquele que usamos para lidar com problemas fora da esfera da vida doméstica, ou aquele com que nos deparamos na leitura do jornal ou da revista. Já a "gramática" pode ser um compêndio de regras que normatizam o "bom português", pode ser um instrumento para auxiliar a nossa comunicação, de acordo com nossos propósitos, mas é, sobretudo, o conhecimento internalizado, intuitivo, que todo falante possui acerca da sua língua. Isso tudo esclarecido, temos condições para desmentir o equívoco de que não é necessário ensinar português. Uma vez que "português" é apenas uma noção que expressa um conjunto amplo de variedades, ensinar português é ensinar o aluno a transitar de uma variedade a outra, de um estilo a outro. Nesse aspecto, se um profissional defende ser perda de tempo ensinar português é porque desconhece as noções de variação, adequação, estilo e gramática, ou acha que pode subtrair do falante o direito de dominar a variedade em que a literatura, a cultura, o conhecimento e a informação oficial são divulgados.

Ante a existência desse pensamento, é possível concluir que, ainda que a ciência linguística tenha trazido avanços e que, apesar de a sociolinguística oferecer resultados que possam oferecer aplicações ao ensino de língua materna, há um grande abismo entre ensino e pesquisa. Grande parte da bibliografia destinada ao professor, apesar de trazer informações sociolinguísticas, se atém principalmente a questões metodológicas. No entanto, de pouco adianta um professor ter amplo conhecimento de métodos de ensino se não tem acesso a pesquisas sobre o que de fato ocorre na língua que fala. É fato, porém, que professores que não têm conhecimento sobre os fatos da língua que irão ensinar estão sendo formados nos nossos cursos de letras.

Toda essa discussão foi feita com o intuito de apontar para a necessidade de elaboração de programas de ensino de linguística nos cursos de letras que apresentem mais amplamente as contribuições da sociolinguística. Pensamos que existem aspectos que são igualmente importantes e que não podem ser negligenciados num programa de sociolinguística para futuros professores. Esses aspectos dizem respeito a principalmente a (1) variação no sistema gramatical da língua, (2) o tipo de rede sociolinguística em que podem estar inseridas as escolas e (3) a interação professor-aluno em sala de aula. 
Nos parece que o primeiro aspecto anda um pouco ofuscado diante dos aspectos interacionais e sociológicos. No entanto, o professor não pode limitar sua prática à repetição do discurso de que as línguas variam e de que se deve combater o preconceito linguístico. É fundamental que ele primeiramente conheça a língua que vai ensinar a seus alunos em todos os seus aspectos variáveis para que possa sustentar o discurso de legitimação da variação e de combate ao preconceito. É necessário saber, por exemplo, como funciona o sistema de concordância em sua língua e como se dão as permutações fonéticas nas diversas variedades de fala. É fundamental, enfim, ter conhecimento tanto do uso do português quanto da sua estrutura. Sem o conhecimento da lógica da variação e de toda a sua amplitude, o professor não compreenderá o fenômeno variável e apenas substituirá o discurso do purismo linguístico pelo discurso do politicamente correto, porque assim foi doutrinado.

Ao deixar o plano do velho purismo para transitar no plano do politicamente correto, o professor não avança para além de uma atitude valorativa em relação à língua. O que era considerado "errado" no discurso purista passará a ser "apenas inadequado", no plano dos termos politicamente corretos, revelando que o professor não se apropriou de um entendimento crítico da língua. Somente conhecendo a variação, os dados variáveis, sua distribuição e seus mecanismos de funcionamento é que o professor poderá finalmente sair do nível valorativo do conhecimento da língua e passará a reconhecer como legítimas a língua em toda a sua diversidade.

\section{Considerações finais}

Nosso trabalho buscou contribuir para o ensino de língua materna a partir da revisão de algumas abordagens sociolinguísticas. Vivemos em uma época em que a gramática normativa vem perdendo sua credibilidade no cenário de ensino e, ao mesmo tempo, inovações na pedagogia da língua ainda não se constituem um corpo coeso de propostas ou mesmo não desfrutam de boa receptividade. Acreditamos que os avanços trazidos pelos estudos da linguagem no contexto social podem auxiliar na orientação dos professores quanto à delimitação de suas estratégias de ensino.

Da pergunta central deste artigo, derivaram-se outras. A primeira delas diz respeito à relação teoria-prática. Na medida em que apresentamos os temas e os achados das principais áreas dos estudos sociolinguísticos, uma questão torna-se inevitável: (a) Como fazer a ponte entre tais achados e o ensino da língua materna? Essa preocupação parece estar relacionada ao 
fazer acadêmico e deve estar presente na agenda de responsabilidades do professor que atua na formação universitária. Isso significa dizer que cabe ao professor de linguística orientar seu aluno, futuro professor de português, na seleção de leituras das quais possa aproveitar aspectos que lhes serão úteis em sala de aula. É importante ter em mente, nesse aspecto, que o equilíbrio entre as diferentes abordagens sociolinguísticas é mais importante que o aprofundamento teórico de um mesmo assunto. Ou seja, de nada adianta um professor de linguística municiar seu aluno em questões de política linguística e negligenciá-lo quanto a leituras sobre aspectos da variação estrutural da língua. Não podemos formar professores com um bom discurso sobre inclusão, mas que se sentem embaraçados quando o assunto é o conhecimento sobre a língua que se fala no Brasil. Outro ponto fundamental, nesse sentido, é que o professor de sociolinguística promova um intenso trabalho com dados variáveis da língua. Se o aluno universitário somente for treinado para sustentar o discurso sobre o respeito às variedades, sem conhecê-las de fato, não estará sendo honesto em relação à sua prática. Desse modo, apenas estará atendendo a exigência de performar um comportamento normatizado pela academia.

Também derivadas da questão central deste trabalho são as perguntas (b) e (c), as quais devem estar presentes no fazer diário do professor de português na escola. Tais perguntas são: (b) Como equacionar a dinâmica variação/ensino da norma nas salas de aulas? (c) De posse de um repertório teórico, o que o professor de língua materna deve apresentar e o que não deve apresentar aos seus alunos? Em relação à questão (b), nos parece que variação linguística e ensino da norma culta não são coisas excludentes. Admitir a variação não implica negarmos a necessidade de se ensinar uma norma unificadora; muito pelo contrário: entender a variação é admitir a necessidade de uma espécie de "língua franca", ensinada na escola a fim de democratizar o acesso à informação e ao conhecimento, independentemente da língua falada em casa por um indivíduo. A questão (c) parece um tanto mais delicada. A linguística como ciência obteve parte de seu prestígio no confronto que travou com a gramática tradicional, um estudo não científico da linguagem. Isso levou muitos professores e alunos de letras a pensar que a linguística substituiria a gramática quando, na verdade, as duas disciplinas têm domínios diferentes. Nesse ponto, é importante ressaltar que não é papel do professor de português levar conteúdos de linguística para a sala de aula de língua materna. O papel da linguística, na formação do professor é, antes, o de um conjunto de conhecimentos com a finalidade de ampliar e criticizar o entendimento da língua que falamos e ensinamos. Seu papel é, pois, o de orientar o professor na elaboração de seus conteúdos didáticos e na sua atitude em sala de aula. Um 
professor bem orientado certamente saberá traçar um plano de aula inclusivo e que contemple os conhecimentos de gramática.

Esperamos, com esse artigo, estimular os professores a buscar nos trabalhos de descrição linguística material para melhor trabalhar com o ensino de uma língua real. Tais trabalhos só fazem sentido se servirem para a compreensão do funcionamento da língua, compreensão essa fundamental para o professor de português. Se não houver uma ponte entre toda a pesquisa feita na academia e o ensino nas escolas, os dados e as análises sociolinguísticas acabarão por se tornar um descritivismo vazio.

Por outro lado, não basta condenar a gramática normativa e admitir passivamente a existência da realidade variável. Esta parece uma postura acomodada. É necessário colocar no lugar da prescrição de uma língua ideal o estudo de uma gramática de usos. Para isso, é urgente apresentar aos estudantes de Letras as forças internas e externas que regem cada fenômeno variável, para que construam autonomamente a crença de que a língua é dinâmica. Do contrário, se não apresentarmos as evidências da variação (contidas nos dados estruturais, nos dados de uso e nos textos que questionam as estruturas sociais) e, ao mesmo tempo, exigirmos que nossos alunos defendam a diversidade linguística, estaremos mais uma vez contribuindo para um ensino de português dogmático e doutrinário.

\section{Referências bibliográficas}

AMARAL, A. O dialeto caipira: gramática e vocabulário. São Paulo: Hucitec, 1982, $4^{\text {a }}$ edição [1ª edição: 1920].

BORTONI-RICARDO, S. M. The urbanization of rural dialect speakers: a sociolinguistic study in Brazil. Cambridge: Cambridge University Press, 1985.

Educação em Língua materna. A sociolinguística na sala de aula. São Paulo:

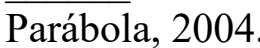

CARDOSO, S. A. M. Geolinguística. Tradição e modernidade. São Paulo: Parábola Editorial, 2010.

HYMES, D. Communicative competence. In: PRIDE, J. B. \& HOLMES, S. (orgs.). Sociolinguistics. Harmondsworth: Penguin Books, 1972.

LABOV, W. The social stratification of English in New York city. Washington, D.C., Center for Applied Linguistics, 1966. 
NASCENTES, A. O linguajar carioca. Rio de Janeiro: Organização Simões, 1953, $2^{\mathrm{a}}$ edição [1 $1^{\mathrm{a}}$ edição: 1923] 